\title{
Pediatric acute lymphoblastic leukemia
}

\begin{abstract}
Progress in the understanding and treatment of pediatric acute lymphoblastic leukemia over the past 60 years has been remarkable and it is now expected that $80-85 \%$ of children diagnosed will be cured of this disease. This review article discusses risk factors, classification, presentation, risk groups, treatment, outcome, and long-term complications of therapy. Pediatric cancer studies serve as a model for national and international group cooperation to treat uncommon diseases.
\end{abstract}

Keywords: pediatric leukemia, review, key aspects, cooperative group participation
Volume 5 Issue 3 - 2017

\section{Theodore Zwerdling}

Department of Pediatrics, Wright Street Medical Center, USA

Correspondence: Theodore Zwerdling, Department of Pediatrics, Elica Health Centers, Wright Street Medical Center, 1750 Wright Street, Sacramento CA 95825, USA, Fax 916-779756I,Tel 855-354-2242, Email tzwerdling@elicahealthcare.org

Received: July 12, 2017 | Published: September 28, 2017
Abbreviations: BMF, berlin-muenster-frankfort; CNS, central nervous system; COG, children's oncology group; CMV, cytomegalovirus; FAB, french-american-british; HIV, human immunodeficiency virus; MRD, minimal residual disease; pALL, pediatric acute lymphoblastic leukemia; SCT, stem cell transplantation; WBC, white blood cell; 6-MP, 6-mercaptopurine

\section{Introduction}

This review will focus on pediatric acute lymphoblastic leukemia (pALL), highlighting risk factors, classification, presentation, risk group assignment and treatment stratification, treatment, outcome, and long-term consequences of therapy. Other forms of pediatric leukemia, such as acute and chronic myeloid leukemia are not reviewed. The reader is referred to several recent publications reviewing these topics. ${ }^{1-4}$ No discussion of pediatric leukemia would be complete without reference to the scientific principles and organizations which have taken this complex disease, largely fatal in the 1960's, now mostly curable less than 60 years later.

\section{Discussion}

\section{Background}

pALL comprises a group of malignancies involving B- and T-lineage cells occurring from birth to age 21years (some protocols allow participation of patients up to age 30years). While the upper limit of age is somewhat arbitrary, biologic characteristics of these disorders change with increasing age. As will be discussed, age remains one initial variable defining risk stratification and prognosis. There are approximately 3,100 new cases of pALL in North America per year, a number which has been increasing over the past decades. pALL presents as a bimodal distribution from $\sim 80$ cases/million/year, ages 1-4years, to 24 cases/million/year, ages 10-14years. This disease effects caucasian children more commonly than other races. ${ }^{6,7}$

Early researchers realized that with small numbers of new patients and given the complexity of the disease process, little progress would be possible in terms of understanding and treatment by single institutional studies. Therefore, in the 1960's, efforts were mounted to develop national co-operative groups charged with studying science, classification, treatment, and outcome of pALL. Currently the Children's Oncology Group (COG) is responsible for providing state of the art protocols, data management and studying biology of pALL, now on an international scope ${ }^{8}$ COG protocols, for all forms of childhood cancer, are developed by statisticians, nurses, physicians, researchers, psychologists, and many others who all play important roles in their formation and implementation. Other study groups perform similar functions in other parts of the world, such as the European Berlin-Muenster-Frankfort (BMF) group, and North America, for example, St. Jude Children's Research Hospital.

\section{Known risk factors involved in development of pALL}

Risk factors for the vast majority of children and adolescents developing pALL remain mostly unknown at the present time. However, a few well characterized disorders can be associated with a higher risk of developing leukemia. ${ }^{9}$ For example, the most common, known genetic abnormality is Down syndrome or Trisomy 21 . These children have a cumulative risk of approximately $2 \%$ by age 5 years of developing leukemia. ${ }^{10,11}$ Several other genetic conditions which demonstrate a high incidence of pALL, have in common DNA abnormalities such as susceptibility to increased breakage, and abnormally functioning repair enzymes. Table 1 outlines some of these syndromes. Other risk factors include maternal and post-natal exposure to X-rays, and a history of chemotherapy. ${ }^{20-23}$

Table I Genetic disorders associated with pALL

\begin{tabular}{ll}
\hline Disorder & Reference \\
\hline Neurofibromatosis & 12 \\
Ataxic Telangiectasia & 13 \\
Li-Fraumeni Syndrome & $9,14,15$ \\
Mismatch Repair Deficiency & 16 \\
Fanconi Anemia & 17 \\
Bloom Syndrome & 18,19 \\
\hline
\end{tabular}

\section{Classification}

Early classification schema for pALL relied on criteria using the French-American-British (FAB) system, based on morphology and other patient characteristics. The FAB system is no longer used as better and more objective methodologies have become clinical standard for classification. These newer schema are based on immunologic analysis of leukemic cells using flow cytometry and molecularly based characteristics of cancer cells. The WHO recognizes the following distinct types of leukemia: ${ }^{24}$ 


\section{B-lymphoblastic leukemia}

i. B-lymphoblastic leukemia with $\mathrm{t}(9 ; 22)(\mathrm{q} 34.1 ; \mathrm{q} 11.2)$; BCRABL1.

ii. B-lymphoblastic $\mathrm{t}(\mathrm{v} ; 11 \mathrm{q} 23.3)$; KMT2A rearranged.

leukemia

with

iii. B-lymphoblastic leukemia with $\mathrm{t}(12 ; 21)(\mathrm{p} 13.2 ; \mathrm{q} 22.1)$; ETV6RUNX1.

iv. B-lymphoblastic leukemia: hyperdiploidy.

v. B-lymphoblastic leukemia: hypodiploidy.

vi. B-lymphoblastic leukemia with $\mathrm{t}(5 ; 14)(\mathrm{q} 31.1 ; \mathrm{q} 32.3)$; IL3IGH.

vii. B-lymphoblastic leukemia with $\mathrm{t}(1 ; 19)(\mathrm{q} 23 ; \mathrm{p} 13.3)$; TCF3PBX1.

viii. Others

\section{T-lymphoblastic leukemia}

Others: A simplified classification separates these leukemias into precursor B-Cell and T-Cell leukemias. The majority of pALL is of B-lineage, which is the focus of this review. Immunophenotyping of leukemic blast cells delineates not only the cell lineage but also the degree of maturation. Precursor B-Cell blasts, which accounts for $\sim 80 \%$ of pALL, are characterized by immuno-reactivity with

Table 2 Common chromosomal translocations associated with PALL monoclonal antibodies to CD19, HLA-DR surface receptors and the presence of cytoplasmic CD79a. CD10 is present on about $90 \%$ of precursor B-cell pALL and its absence is associated with a poor outcome. ${ }^{25}$ The presence of cytoplasmic immunoglobulin or heavy chain is termed pre-B-Cell pALL and finally, true B-cell pALL express surface immunoglobulin, also known as Burkitt leukemia, requiring different treatment. ${ }^{26,27} \mathrm{~T}$-Cell pALL may be distinguished by cytoplasmic CD3 and CD7 and CD2. DNA-based testing is performed as routine part of patient care and is important for risk stratification. Ploidy has emerged as an important determinate of risk assessment and can be evaluated by measuring DNA content of cells (DNA index) or karyotyping. Hyperdiploidy (51 to 65 chromosomes/cell) is found in $25 \%$ of cases of precursor B-cell pALL and is associated with a favorable outcome of treatment. ${ }^{28,29}$ Other ploidy variations are known, including near-haploid (24 to 29 chromosomes/cell) and portents a poor outcome. ${ }^{30}$ Fluorescence in situ hybridization analysis can be of benefit for interphase or metaphase cell preparations. Using this technique, it has been found that trisomy 4 and 10 have a favorable outcome, for example. ${ }^{31}$

Table 2 illustrates some of the many translocations found in pALL and associated features. Other DNA analyses are important predictors of toxicity including polymorphisms of the gene responsible for metabolism of 6-mercaptopurine (6-MP), a commonly used treatment. ${ }^{36}$ Patients found to be homozygous for variant alleles of the TMTP gene tolerate much lower doses of 6-MP and must be dose reduced to prevent excessive toxicity. Other polymorphisms are known, but few have been tested sufficiently to direct therapy.

\begin{tabular}{|c|c|c|c|}
\hline Translocation & Involved genes & Prognostic significance & Notes/reference \\
\hline $\mathrm{t}(\mid 2 ; 2 \mathrm{I}(\mathrm{p} \mid 3.2 ; \mathrm{q} 22)$. & ETV6-RUNXI & Favorable & 32,33 \\
\hline $\mathrm{t}(9 ; 22)(q 34.1 ; q \mid I .2)$ & BCR-ABLI $(\mathrm{Ph}+)$ & Favorable & Tyrosine kinase inhibitors; ${ }^{34}$ \\
\hline $\mathrm{t}(\mathrm{v} ; \mathrm{I}$ q 23.3) & MLL & Poor & Infants, high WBC ${ }^{35}$ \\
\hline$(1 ; 19)(q 23 ; p \mid 3.3)$ & TCF3-PBXI & Variable & 27 \\
\hline $\mathrm{t}(8 ; 14)(q 24 ; 32)$ & $M Y C-\lg H$ & Good & 26 \\
\hline
\end{tabular}

\section{Clinical presentation and evaluation}

The clinical presentation of pALL relates to the signs and symptoms of bone marrow replacement by malignant blast cells and subsequent loss of normal cellular elements. These signs and symptoms typically include fatigue, appearing pale, bleeding (petechiae), adenopathy, hepatomegaly, splenomegaly and fevers. However, at other times patients present with fever, infections, complaints of bone pain, or inability to walk. Very young children or babies may present with irritability, poor appetite and weight loss. For children with central nervous system disease (CNS) cranial nerve abnormalities may be seen. T-Cell leukemia presents with difficulty breathing or wheezing, caused by an enlarged thymus gland and represents a pediatric emergency. Compression of the airway can result in life threatening respiratory failure and/or hypoxia. Primary care providers, as well as Emergency Department physicians, must recognize not all wheezing is due to asthma. Initiation of steroid therapy, a common practice for patients with asthma, can result in rapid tumor lysis, metabolic disturbances and death prior to start of therapy.

Some males will present with testicular masses, representing overt leukemic infiltration of the testes. ${ }^{37} \mathrm{~A}$ similar presentation in females with ovarian masses is much less common. With a clinical suspicion of leukemia, an extensive laboratory investigation is required prior to any therapy. Complete blood count with differential, metabolic panel, chest X-ray, urine analysis, and coagulation studies should all be performed. Additional studies include bone marrow aspiration and biopsy, and lumbar puncture to determine extent of CNS disease. Other studies may be necessary guided by individual patient requirements. Blood for infectious evaluation should be obtained and can include blood cultures and titers for viral infectious agents such as Cytomegalovirus (CMV), Human Immunodeficiency Virus (HIV) and others. If the patient presents with high-risk features, which will require future anthracycline therapy, consideration to performance of an echocardiogram should be given.

Blood analysis for immunophenotyping, chromosomal analysis, and molecular studies are now routine part of evaluating a child with leukemia. Some research protocols require additional blood, bone marrow and spinal fluid studies to be obtained prior to start of therapy. Research studies not needed for clinical care should be discussed with parents or guardians prior to their collection. Many patients are offered treatment according to research protocols, most of the time welcomed by parents/guardians, so it is important to talk with families, including the child, about this possibility to minimize delays in treatment or loss of research study participation which may be available. 


\section{Risk groups and treatment stratification}

Risk group and treatment stratification involving children with pALL is an ongoing and evolving process. Early studies emphasized age, white blood cell (WBC) counts and involvement of the CNS. With wide spread availability of flow analysis and immunophenotyping, additional information yielded a better understanding of the disease and grouping of patients to receive more specific therapies. Chromosomal analysis and DNA studies further improved the classification of pALL. In the past decade, response to treatment has become a powerful indicator of the type of therapy an individual patient will derive the best risk to benefit ratio. Over the many research protocols correlating these variables and, linking uniform treatments to outcome, multiple risk strata are now defined. Patients may begin treatment in one risk group only to change to a different one as more information and their individual responses to treatment become known. This multi-tier, individualized approach allows directing higher risk patients to be treated more aggressively but sparing lower risk patients additional therapy which may not be needed. The following are some of the important indicators used to assign a patient to risk strata:

\section{Initial risk classification}

Age: this continues to be important for initial stratification with the most favorable group of children from 1 year to 10 years. Very young $(<1$ year) and teenage patients ( $>10$ years) do not have as favorable outcome.

WBC count: First WBC count, prior to any intervention is used for initial stratification with $<50,000 / \mathrm{cc}$ favorable. Higher WBC count is associated with T-Cell leukemia and is a high risk feature.

Testicular involvement: Testicular involvement may present as a mass and it is controversial if this effects prognosis. ${ }^{37}$

CNS involvement: Greater than 5blast cells/cc or the presence of cranial nerve palsy/paralysis indicate overt disease. Formulas exist to correct for traumatic lumbar punctures..$^{38,39}$

Light microscopy/immunophenotyping of blast cells: Morphology evaluation of leukemic cells confirms the diagnosis and usually rules out other forms of leukemia. Flow analysis, allows rapid immunophenotyping classification of the leukemia and is now possible with results available within 24 hours. It is also a requirement for most research protocols.

\section{Additional risk classification elements}

DNA Studies: Ploidy, karyotype and DNA analysis for cryptic translocations results are also important to determine risk classification, results usually available during the first few weeks of treatment. These results may change risk category assignment. For example, the presence of a $\mathrm{Ph}+\mathrm{pALL}$ is a high-risk factor and requires different therapies.
End of induction chemotherapy (4 weeks): With over 95\% of children entering remission, remission status as an indicator of possible cure has been minimized (patients not entering remission at this time fare poorly). Additional response indicators, either more sensitive at end of induction or at earlier time points to identify risk categories were therefore needed. ${ }^{40,41}$

Minimal residual disease (MRD): Determinations of MRD, by flow cytometry analysis at several time points in therapy, are now routine part of clinical practice and used to guide therapy. It is controversial at which time points and what space (peripheral blood or bone marrow) to best make use of MRD. ${ }^{41-49}$

Final risk group assignment is of importance as it allows rational assignment of patients to therapies designed to balance risks of therapy vs maximizing possibilities of cure ${ }^{50}$ Chemotherapy remains highly toxic for these children not only while receiving treatment, but now equally important, for long-term effects. Based on this information patients are assigned to low, standard, high and very high risk categories. Different criteria are applied by the various co-operative groups to determine risk strata, and therefore, treatment. For example, the European Berlin-Muenster-Frankfort (BMF) group bases risk assignment on response to therapy by determining MRD at weeks 5 and $12 .{ }^{42,46}$ Only patients with $\mathrm{Ph}(+)$ and $\mathrm{t}(4 ; 11)$ are considered high risk, irrespective of response. The COG combines other factors to define patient's prognostic groups including age, WBC count, genetic abnormalities, MRD at various time points and absence of Down syndrome and pre-treatment steroids. ${ }^{41}$

\section{Treatment principals}

After completion of the diagnostic evaluation, and prior to initiation of chemotherapy, patients must be readied for treatment, which means several associated medical issues must be addressed. Many patients will have severe anemia and thrombocytopenia, problems treated with irradiated blood products. For patients presenting with fever, or other signs of infection, and low absolute neutrophil count, presumptive institution of broad spectrum antibiotics is warranted until culture results are known to be negative or infection treated. Placement of a central venous access devise is usually required to allow delivery of chemotherapy, procuring blood sampling, and to be used for instillation of anesthesia required for multiple lumbar punctures and bone marrow examinations. Patients should receive hydrating fluids and allopurinol to minimize metabolic complications associated with initiation of treatment and possible tumor lysis syndrome. Prophylaxis for Pneumocystis jirovecii is also begun prior to discharge. During the initial hospitalization significant resources are employed including nursing, social services, play therapists and others. These children are approached by a team to help educate and guide patients and parents/ guardians through complex treatments and emotional concerns they may have. ${ }^{8}$ An example of treatment is shown in Table 3 for patients with standard risk pALL. Different treatments may be recommended based on the above defined risk strata.

Table 3 Example of standard risk treatment for PALL*

\begin{tabular}{|c|c|c|}
\hline Phase of therapy & Duration & Treatments \\
\hline Induction & 4Weeks & Vincristine, steroid, asparaginase, intrathecal chemotherapy \\
\hline Consolidation & 4weeks & Vincristine, 6-mercaptopurine, intrathecal chemotherapy \\
\hline Interim Maintenance I & 8weeks & Vincristine, methotrexate, intrathecal chemotherapy \\
\hline Delayed Intensification & 8weeks & $\begin{array}{l}\text { Vincristine, steroid, doxorubicin, asparaginase, cyclophosphamide, 6-thioguanine, cytarabine, } \\
\text { intrathecal chemotherapy }\end{array}$ \\
\hline Interim Maintenance II & 8weeks & Vincristine, intrathecal chemotherapy \\
\hline Maintenance & 2years- female, 3years- male & Vincrisitne, steroid, 6-mercaptopurine, intrathecal chemotherapy \\
\hline
\end{tabular}




\section{Treatment of relapsed pALL}

While most children and adolescents will be cured of disease undergoing current treatment plans, $5-20 \%$ are expected to relapse. ${ }^{50-53}$ Relapsed pALL is thus more common than many other cancers diagnosed in children and adolescents. The outcome for many of these children remains poor; however several characteristics have been identified, which in turn suggest therapeutic options. Site of relapse is important with patients having extra-medullary relapse fairing better than those with marrow involvement. ${ }^{54-57}$ Children relapsing early $(<18$ months from start of treatment) due particularly poorly while late relapses ( $>36$ months) have better outcomes. Patients with T-Cell disease also fair poorly. ${ }^{54}$ Using these prognostic factors, treatment consists of re-induction chemotherapy (4weeks) and determination of response. For patients with early relapse recommendations for Stem Cell Transplantation (SCT) using allogeneic or matched unrelated donors are considered ${ }^{58-60}$ MRD should be minimal prior to SCT, even if it requires additional chemotherapy as higher residual disease portents SCT failure and recurrence of disease. ${ }^{61-63}$ For patients relapsing $>18$ months into treatment, continuation of chemotherapy can be successful. Current cooperative group protocols are aimed at introducing novel drugs, such as Blinatumomab and Inotuzumab, in hopes of improving outcomes and also to evaluate their potential in upfront therapy. ${ }^{64,65}$

Most recently, the use of engineered T-Cells has entered clinical practice ${ }^{66}$ In this study lentiviral transduced autologous T- cells were redirected to attack leukemic blasts which were CD19 positive, a common surface antigen on most pALL of B-lineage origin. Twentyseven of 30 highly refractory patients went into remission, $67 \%$ lasting at least 6 months. Cytokine release syndrome occurred in $27 \%$ of patients and could be treated with an anti-IL-6 monoclonal antibody. Further trials of this new therapy will be needed to understand its place in the therapeutic armamentarium.

\section{Long-term outcome for cured patients}

With large numbers of children treated for and cured of pALL, further attention and emphasis has been placed on long-term consequences of treatment. For children 12years of age who are healthy and never had leukemia, life expectancy is about 88.4 years for males and 90.2 years for females. ${ }^{67}$ Clearly, the long-term consequences are going to have a profound impact on the future of patients treated for leukemia. For example, the cumulative incidence of chronic medical problems, including death, for children treated for leukemia is approximately $20 \%$ by age 30 and over $50 \%$ at age 50 , compared to non-treated siblings of $10 \%$ and $25 \%$, respectively. ${ }^{68-70}$ Furthermore, these curves are not flat and the cumulative incidence continues to increase as these patients age.

Therefore long-term follow-up assumes an important part of medical care for these children, with problems reported for nearly every organ system. Table 4 highlights some of these ongoing health issues for this population. A comprehensive review of longterm health problems, and how to care for them, may be found at the COG web site and in several recent reviews. ${ }^{8,70-72}$ However important medical complications are, other social and societal factors arise as well. These patients may be denied insurance or required to pay higher premiums. There have been instances of discriminatory hiring practices making employment more difficult. Critical stages of normal childhood social development maybe interrupted and replaced with interactions typically occurring at older ages. Self esteem can be altered and effects on families, both social and economic, experienced. Finally, a growing problem for any child treated for cancer whether it is leukemia or other forms, relates to difficulties in finding health care providers after they transition to adult services. Specific programs to facilitate changing from pediatric to adult care models are now in place at larger institutions, but not available everywhere. ${ }^{73,74}$ It is known from other long-term follow-up studies that this population will have more medical needs as they age and require care provider's who are able to recognize these and other yet unknown, complications of treatment. ${ }^{70}$

Table 4 Some long-term complications of treatment for PALL

\begin{tabular}{lll}
\hline Organ system & Therapy implied & Effect \\
\hline $\begin{array}{l}\text { Central Nervous } \\
\text { System }\end{array}$ & Vincristine & Neuropathy \\
$\begin{array}{l}\text { Central Nervous } \\
\text { System }\end{array}$ & Methotrexate & $\begin{array}{l}\text { Encephalopathy } \\
\text { Cognitive Dysfunction }\end{array}$ \\
$\begin{array}{l}\text { Central Nervous } \\
\text { System }\end{array}$ & Radiation & Cognitive Dysfunction \\
Cardiovascular & Anthracycline/Radiation & $\begin{array}{l}\text { Arrhythmia } \\
\text { Congestive Heart Failure }\end{array}$ \\
Pulmonary & Stem Cell Transplant & Bronchiolitis Obliterans \\
Gastrointestinal & $\begin{array}{l}\text { Stem Cell Transplant } \\
\text { (Graft-vs-Host Disease) }\end{array}$ & Esophageal Strictures \\
Hepatic & Methotrexate & Hepatitis \\
Hepatic & 6-mercaptopurine, & $\begin{array}{l}\text { Hyperbilirubinemia } \\
\text { 6-thioguanine }\end{array}$ \\
Reproductive & Cyclophosphamide \\
Renal & Cyclophosphamide & Infertility \\
Lympho- & & Renal Tubular Acidosis \\
hematopoietic & & Second malignancy \\
\hline
\end{tabular}

\section{Conclusion}

The past 60years have seen remarkable improvements in understanding, treatment and, most importantly, survival for children and adolescents with pALL, yet much work remains. ${ }^{1,50}$ Curing these children and adolescents has come at a high price with respect to longterm sequela. Fully integrating these patients into society and allowing them to reach full potential seems to be a next goal for consideration. Additional inroads, working with our colleagues who care for adults, continue to be an important step and an ongoing challenge. Many individuals deserve recognition for their contributions to our current state of understanding and treatment, but none more so than the patients and their parents/guardians who have and continue participation in clinical trials. Well designed, prospective, randomized clinical trials remain the mainstay of progress and will likely be for the foreseeable future. Finally, can we speculate in the future better therapies will result in higher cure rates, with less toxicity and more tailored treatments? The answer is yes. And even more daring, can we see a time when we will be able to prevent this disease from ever happening?

\section{Acknowledgements}

I wish to acknowledge all the nurses, social workers, psychologists, play therapists, pharmacists, physicians, researchers, statisticians, and data managers all of whom contributed to this review. I am indebted to the patients, parents and/or guardians for their participation in research studies. 


\section{Conflict of interest}

The author declares no conflict of interest.

\section{References}

1. Childhood acute myeloid leukemia/Other myeloid malignancies treatment $(\mathrm{PDQ} \otimes)$ : health professional version. $P D Q$ Pediatric Treatment Editorial Board, PDQ Cancer Information Summaries. Bethesda, USA: National Cancer Institute; 2017.

2. Rubnitz JE. Current management of childhood acute myeloid leukemia. Paediatr Drugs. 2017;19(1):1-10.

3. Suttorp M, Eckardt L, Tauer JT, et al. Management of chronic myeloid leukemia in childhood. Curr Hematol Malig Rep. 2012;7(2):116-124.

4. Ampatzidou M, Papadhimitriou SI, Goussetis E, et al. Chronic myeloid leukemia (CML) in children: classical and newer therapeutic approaches. Pediatr Hematol Oncol. 2012;29(5):389-394.

5. Möricke A, Zimmermann M, Reiter A, et al. Prognostic impact of age in children and adolescents with acute lymphoblastic leukemia: data from the trials ALL-BFM 86, 90, and 95. Klin Padiatr. 2005;217(6):310-320.

6. Shah A, Coleman MP. Increasing incidence of childhood leukaemia: a controversy re-examined. Br J Cancer. 2007;97(7):1009-1012.

7. Howlader N, Noone AM, Krapcho M, et al. SEER Cancer Statistics Review, 1975-2014. Bethesda, USA: National Cancer Institute; 2017.

8. https://childrensoncologygroup.org/

9. Malkin D, Nichols KE, Zelley K, et al. Predisposition to pediatric and hematologic cancers: a moving target. Am Soc Clin Oncol Educ Book. 2014;2014:e44-55.

10. Whitlock JA. Down syndrome and acute lymphoblastic leukaemia. British Journal of Haematology. 2006;135 (5):595-602.

11. Hasle H. Pattern of malignant disorders in individuals with Down's syndrome. Lancet Oncol. 2001;2(7):429-436.

12. Stiller CA, Chessells JM, Fitchett M. Neurofibromatosis and childhood leukaemia/lymphoma: a population-based UKCCSG study. Br J Cancer. 1994;70(5):969-972.

13. Taylor AM, Metcalfe JA, Thick J, et al. Leukemia and lymphoma in ataxia telangiectasia. Blood.1996;87(2):423-438.

14. Powell BC, Jiang L, Muzny DM, et al. Identification of TP53 as an acute lymphocytic leukemia susceptibility gene through exome sequencing. Pediatr Blood Cancer. 2013;60(6):E1-E3.

15. Hof J, Krentz S, van Schewick C, et al. Mutations and deletions of the TP53 gene predict nonresponse to treatment and poor outcome in first relapse of childhood acute lymphoblastic leukemia. J Clin Oncol. 2011;29(23):3185-3193.

16. Ripperger T, Schlegelberger B. Acute lymphoblastic leukemia and lymphoma in the context of constitutional mismatch repair deficiency syndrome. Eur J Med Genet. 2016;59(3):133-142.

17. Alter BP. Cancer in Fanconi anemia, 1927-2001. Cancer. 2003;97(2):425440.

18. Passarge E. Bloom's syndrome: the German experience. Ann Genet. 1991;34(3-4):179-197.

19. Ellis Nathan, German J. Bloom Syndrome. In: Vogelstein B, et al. editors. The Genetic Basis of Human Cancer. 22nd ed. USA: McGrawHill; 2002. p. 267-288.

20. Taub JW, Konrad MA, Ge Y, et al. High frequency of leukemic clones in newborn screening blood samples of children with B-precursor acute lymphoblastic leukemia. Blood. 2002;99(8):2992-2996.
21. M Greaves. Natural history for pediatric acute leukemia. Blood. 1993;82(4):1043-1051.

22. Draper GJ, Heaf MM, Kinnier Wilson LM. Occurrence of childhood cancers among sibs and estimation of familial risks. J Med Genet. 1977;14(2):81-90.

23. Shu XO, Gao YT, Brinton LA, et al. A population-based case-control study of childhood leukemia in Shanghai. Cancer. 1988;62(3):635-644.

24. Arber DA, Orazi A, Hasserjian R, et al. The 2016 revision to the World Health Organization classification of myeloid neoplasms and acute leukemia. Blood. 2016;127(20):2391-2405.

25. Dakka N, Bellaoui H, Bouzid N, et al. CD10 AND CD34 expression in childhood acute lymphoblastic leukemia in Morocco: clinical relevance and outcome. Pediatr Hematol Oncol. 2009;26(4):216-231.

26. Goldman S, Smith L, Galardy P, et al. (Rituximab with chemotherapy in children and adolescents with central nervous system and/or bone marrow-positive Burkitt lymphoma/leukaemia: a Children's oncology group report. Br J Haematol. 2014;167(3):394-401.

27. Andersen MK, Autio K, Barbany G, et al. Paediatric B-cell precursor acute lymphoblastic leukaemia with $\mathrm{t}(1 ; 19)(\mathrm{q} 23 ; \mathrm{p} 13)$ : clinical and cytogenetic characteristics of 47 cases from the Nordic countries treated according to NOPHO protocols. Br J Haematol. 2011;155(2):235-243.

28. Paulsson K, Johansson B. High hyperdiploid childhood acute lymphoblastic leukemia. Genes Chromosomes Cancer. 2009;48(8):637660.

29. Dastugue N, Suciu S, Plat G, et al. Hyperdiploidy with 58-66 chromosomes in childhood B-acute lymphoblastic leukemia is highly curable: 58951 CLG-EORTC results. Blood. 2013;121(13):2415-2423.

30. Harrison CJ, Haas O, Harbott J, et al. Detection of prognostically relevant genetic abnormalities in childhood B-cell precursor acute lymphoblastic leukaemia: recommendations from the biology and diagnosis committee of the international berlin-frankfürt-Münster study group. Br J Haematol. 2010;151(2):132-142.

31. Harris MB, Shuster JJ, Carroll A, et al. Trisomy of leukemic cell chromosomes 4 and 10 identifies children with B-progenitor cell acute lymphoblastic leukemia with a very low risk of treatment failure: a pediatric oncology group study. Blood. 1992;79(12):3316-3324.

32. Rubnitz JE, Wichlan D, Devidas M, et al. Prospective analysis of TEL gene rearrangements in childhood acute lymphoblastic leukemia: a Children's Oncology Group study. J Clin Oncol. 2008;26(13):21862191.

33. Bhojwani D, Pei D, Sandlund JT, et al. ETV6-RUNX1-positive childhood acute lymphoblastic leukemia: improved outcome with contemporary therapy. Leukemia. 2012;26(2):265-270.

34. Biondi A, Schrappe M, De Lorenzo P, et al. Imatinib after induction for treatment of children and adolescents with Philadelphia-chromosomepositive acute lymphoblastic leukaemia (EsPhALL): a randomised, open-label, intergroup study. Lancet Oncol. 2012;13(9):936-945.

35. De Lorenzo P, Moorman AV, Pieters R, et al. Cytogenetics and outcome of infants with acute lymphoblastic leukemia and absence of MLL rearrangements. Leukemia. 2014;28(2):428-430.

36. McLeod HL, Coulthard S, Thomas AE, et al. Analysis of thiopurine methyltransferase variant alleles in childhood acute lymphoblastic leukaemia. British Journal of Haematology. 1999;105(3):696-700.

37. Hijiya N, Liu W, Sandlund JT, et al. Overt testicular disease at diagnosis of childhood acute lymphoblastic leukemia: lack of therapeutic role of local irradiation. Leukemia. 2005;19(8):1399-1403.

38. Gajjar A, Harrison PL, Sandlund JT, et al. Traumatic lumbar puncture at diagnosis adversely affects outcome in childhood acute lymphoblastic leukemia. Blood. 2000;96(10):3381-3384. 
39. Bürger B, Zimmermann M, Mann G, et al. Diagnostic cerebrospinal fluid examination in children with acute lymphoblastic leukemia: significance of low leukocyte counts with blasts or traumatic lumbar puncture. $J$ Clin Oncol. 2003;21(2):184-188.

40. Vrooman LM, Silverman LB. Childhood acute lymphoblastic leukemia: update on prognostic factors. Curr Opin Pediatr. 2009;21(1):1-8.

41. Schultz KR, Pullen DJ, Sather HN, et al. Risk- and response-based classification of childhood B-precursor acute lymphoblastic leukemia: a combined analysis of prognostic markers from the pediatric oncology group (POG) and children's cancer group (CCG). Blood 2007;109(3):926-935.

42. Conter V, Bartram CR, Valsecchi MG, et al. Molecular response to treatment redefines all prognostic factors in children and adolescents with B-cell precursor acute lymphoblastic leukemia: results in 3184 patients of the AIEOP-BFM ALL 2000 study. Blood. 2010;115(16):3206-3214.

43. Griffin TC, Shuster JJ, Buchanan GR, et al. Slow disappearance of peripheral blood blasts is an adverse prognostic factor in childhood $\mathrm{T}$ cell acute lymphoblastic leukemia: a pediatric oncology group study. Leukemia. 2000;14(5):792-795.

44. Basso G, Veltroni M, Valsecchi MG, et al. Risk of relapse of childhood acute lymphoblastic leukemia is predicted by flow cytometric measurement of residual disease on day 15 bone marrow. J Clin Oncol. 2009;27(31):5168-5174.

45. Pui CH, Pei D, Coustan-Smith E, et al. Clinical utility of sequentia minimal residual disease measurements in the context of risk-based therapy in childhood acute lymphoblastic leukaemia: a prospective study. Lancet Oncol. 2015;16(4):465-474.

46. Schrappe $M$, Valsecchi $M G$, Bartram $C R$, et al. Late MRD response determines relapse risk overall and in subsets of childhood T-cell ALL: results of the AIEOP-BFM-ALL 2000 study. Blood. 2011;118(8):20772084

47. Bartram J, Wade R, Vora A, et al. Excellent outcome of minimal residual disease-defined low-risk patients is sustained with more than 10 years follow-up: results of UK paediatric acute lymphoblastic leukaemia trials 1997-2003. Arch Dis Child. 2016;101(5):449-454.

48. Vora A, Goulden N, Mitchell C, et al. Augmented post-remission therapy for a minimal residual disease-defined high-risk subgroup of children and young people with clinical standard-risk and intermediate-risk acute lymphoblastic leukaemia (UKALL 2003): a randomised controlled trial. Lancet Oncol. 2014;15(8):809-818.

49. Pieters R, De Groot-Kruseman H, Van der Velden V, et al. Successful Therapy reduction and intensification for childhood acute lymphoblastic leukemia based on minimal residual disease monitoring: Study ALL10 from the dutch childhood oncology group. $J$ Clin Oncol. 2016;34(22):2591-2601

50. Hunger SP, Loh ML, Whitlock JA, et al. Children's Oncology Group's 2013 blueprint for research: acute lymphoblastic leukemia. Pediatr Blood Cancer. 2013;60(6):957-963.

51. Uderzo C, Dini G, Locatelli F, et al. Treatment of childhood acute lymphoblastic leukemia after the first relapse: curative strategies. Haematologica. 2001;85(11 Suppl):47-53.

52. Nguyen K, Devidas M, Cheng SC, et al. Factors influencing surviva after relapse from acute lymphoblastic leukemia: a Children's Oncology Group study. Leukemia. 2008;22(12):2142-2150.

53. Raetz EA, Borowitz MJ, Devidas M, et al. Reinduction platform for children with first marrow relapse in acute lymphoblastic lymphoma. $J$ Clin Oncol. 2008;26(24):3971-3978.

54. Gaynon PS, Qu RP, Chappell RJ, et al. Survival after relapse in childhood acute lymphoblastic leukemia: impact of site and time to first relapse- the Children's Cancer Group Experience. Cancer. 1998;82(7):1387-1395.
55. Barredo JC, Devidas M, Lauer SJ, et al. Isolated CNS relapse of acute lymphoblastic leukemia treated with intensive systemic chemotherapy and delayed CNS radiation: a pediatric oncology group study. $J$ Clin Oncol. 2006;24(19):3142-3149.

56. Tallen G, Ratei R, Mann G, et al. Long-term outcome in children with relapsed acute lymphoblastic leukemia after time-point and site-of-relapse stratification and intensified short-course multi-drug chemotherapy: results of trial ALL-REZ BFM 90. J Clin Oncol. 2010;28(14):2339-2347.

57. Ko RH, Ji L, Barnette P, et al. Outcome of patients treated for relapsed or refractory acute lymphoblastic leukemia: a Therapeutic Advances in Childhood Leukemia Consortium study. J Clin Oncol. 2010;28(4):648654.

58. Beck JC, Cao Q, Trotz B, et al. Allogeneic hematopoietic cell transplantation outcomes for children with B-precursor acute lymphoblastic leukemia and early or late BM relapse. Bone Marrow Transplant. 2011;46(7):950-955.

59. Eckert C, Henze G, Seeger K, et al. Use of allogeneic hematopoietic stemcell transplantation based on minimal residual disease response improves outcomes for children with relapsed acute lymphoblastic leukemia in the intermediate-risk group. J Clin Oncol. 2013;31(21):2736-2742.

60. Borgmann A, von Stackelberg A, Hartmann R, et al. Unrelated donor stem cell transplantation compared with chemotherapy for children with acute lymphoblastic leukemia in a second remission: a matched-pair analysis. Blood. 2003;101(10):3835-3839.

61. Bader P, Kreyenberg H, Henze GH, et al. Prognostic value of minimal residual disease quantification before allogeneic stem-cell transplantation in relapsed childhood acute lymphoblastic leukemia: the ALL-REZ BFM study group. J Clin Oncol. 2009;27(3):377-384.

62. Balduzzi A, Di Maio L, Silvestri D, et al. Minimal residual disease before and after transplantation for childhood acute lymphoblastic leukaemia: is there any room for intervention? Br J Haematol. 2014;164(3):396-408.

63. Gandemer V, Pochon C, Oger E, et al. Clinical value of pre-transplant minimal residual disease in childhood lymphoblastic leukaemia: the results of the French minimal residual disease-guided protocol. $\mathrm{Br} J$ Haematol. 2014;165(3):392-401.

64. Franca R, Favretto D, Granzotto M, et al. Epratuzumab and blinatumomab as therapeutic antibodies for treatment of pediatric acute lymphoblastic leukemia: current status and future perspectives. Curr Med Chem. 2017;24(11):1050-1065.

65. Thota S, Advani A. Inotuzumab ozogamicin in relapsed B-cell acute lymphoblastic leukemia. Eur J Haematol. 2017;98(5):425-434.

66. Shannon L Maude, Noelle Frey, Pamela A Shaw, et al. Chimeric antigen receptor T cells for sustained remissions in leukemia. $N$ Engl J Med. 2014;371(16):1507-1517.

67. www.ssa.gov/cgi-bin/longevity.cgi

68. Eshelman D, Landier W, Sweeney T, et al. Facilitating care for childhood cancer survivors: integrating Children's Oncology Group long-term follow-up guidelines and health links in clinical practice. J Pediatr Oncol Nurs. 2004;21(5):271-280.

69. Armstrong GT, Kawashima T, Leisenring W, et al. Aging and risk of severe, disabling, life-threatening, and fatal events in the childhood cancer survivor Study. J Clin Oncol. 2014;32(12):1218-1227.

70. Casillas J, Sakamoto KM. Topics in pediatric leukemia-acute lymphoblastic leukemia and late effects in long-term survivors. MedGenMed. 2005;7(1):22.

71. Turcotte LM, Whitton JA, Friedman DL, et al. Risk of subsequen neoplasms during the fifth and sixth decades of life in the childhood cancer survivor study cohort. J Clin Oncol. 2015;33(31):3568-3575. 
72. Nathan PC, Ness KK, Mahoney MC, et al. Screening and surveillance for second malignant neoplasms in adult survivors of childhood cancer: a report from the childhood cancer survivor study. Ann Intern Med. 2010;153(7):442-451.

73. Casillas J, Oeffinger $\mathrm{KC}$, Hudson $\mathrm{MM}$, et al. Identifying predictors of longitudinal decline in the level of medical care received by adult survivors of childhood cancer: a report from the childhood cancer survivor study. Health Serv Res. 2015;50(4):1021-1042.
74. Nathan PC, Greenberg ML, Ness KK, et al. Medical care in long-term survivors of childhood cancer: a report from the childhood cancer survivor study. J Clin Oncol. 2008;26(27):4401-4409. 